\title{
SEGURANÇA PÚBLICA, VIOLÊNCIA URBANA E EXPANSÃO DO SETOR DE SEGURANÇA PRIVADA NO MUNICÍPIO DO RIO DE JANEIRO
}

\author{
J. P. G. Quintella ${ }^{1}$; J. L. F. Carvalho ${ }^{1}$ \\ 1 Faculdade de Administração e Ciências Contábeis da Universidade Federal do Rio de Janeiro, 21941-914, Rio \\ de Janeiro-RJ, Brasil
}

*josepedro@quintella.com

Artigo submetido em 04/04/2017 e aceito em 07/07/2017

\begin{abstract}
RESUMO
A pesquisa foi norteada pelo objetivo de identificar de que forma, no município do Rio de Janeiro, a deficiência das políticas públicas de segurança influencia o setor privado de segurança. O quadro teórico referencial abrangeu as temáticas da contextualização social e econômica da segurança privada, da institucionalização da segurança privada e do problema da segurança pública na cidade do Rio de Janeiro. A etapa empírica do estudo comportou entrevistas semiestruturadas realizadas junto a informantes-chaves, sendo três dirigentes de diferentes empresas de médio porte do ramo de segurança privada localizadas no município, um oficial de alto escalão da
\end{abstract}

Polícia Militar do Rio de Janeiro, e o presidente de uma organização privada prestadora de serviços de treinamento para civis, militares e forças policiais. Os resultados evidenciam aspectos contraditórios de integração e desarmonia entre o setor privado de segurança e o poder público, bem como levantam questões singulares, tais como a relação de causalidade entre a midiatização da violência e o crescimento do setor, e a antinomia entre amplificação da presença ostensiva do efetivo policial nas ruas e o aumento da sensação de insegurança, que provoca o crescimento da demanda por segurança privada.

PALAVRAS-CHAVE: Segurança privada. Segurança pública. Violência urbana. Criminalidade. Controle social.

\section{PUBLIC SECURITY, URBAN VIOLENCE AND THE GROWTH OF THE PRIVATE SECURITY INDUSTRY IN THE CITY OF RIO DE JANEIRO}

\begin{abstract}
The research was guided by the purpose of identifying how, in the city of Rio de Janeiro, the lack of public security policies affect the private security sector. The referential theoretical framework embraced the themes of social and economic contextualization of private security, the institutionalization of private security and the problem of public security in the city of Rio de Janeiro. The empirical stage of the study included semi-structured interviews with key informants, three of whom were directors of different medium-sized companies in the private security sector located in the municipality, a highranking officer of the Military Police of Rio de Janeiro,
\end{abstract}

and the president of a private organization which provides training services to civilians, military and police forces. The results confirms contradictory aspects of integration and imbalance between the private security sector and the public power, as well as raises unique issues, such as the causal relation between the media role in violence and the growth of the sector, and the antinomy between the amplification of the ostensible presence of the police force on the streets and the increase of the sense of insecurity that causes the growth of the demand for private security.

KEYWORDS: Private security. Public security. Urban violence. Criminality. Social control. 


\section{INTRODUÇÃO}

A violência urbana persevera como um dos mais críticos e inquietantes problemas sociais no Brasil, em que a população "convive há anos com taxas de violência criminal absurdas, que naturalizam quase 60 mil homicídios por ano, mais de 50 mil estupros registrados e padrões operacionais inaceitáveis de letalidade e vitimização" (LIMA, BUENO \& MINGARDI, 2016, p. 64). O custo do crime no Brasil alcançou US\$ 91,4 bilhões em 2014, ou 3,78\% do PIB daquele ano, segundo estudo divulgado no final de 2016 pelo Banco Interamericano de Desenvolvimento (CAVALCANTI, 2017). A violência e a criminalidade denotam questões sociais endêmicas que assestam indistintamente a todos os brasileiros, mormente os mais vulneráveis (ALVES, 2017). Nesse contexto, as temáticas da violência em geral e da criminalidade em particular têm aguçado o interesse de pesquisadores, bem como debates nas esferas social, econômica e política, perante a inépcia institucional em desenvolver e sustentar políticas de segurança que adequadamente respondam a questões concernentes à violência (CARVALHO \& ESPÍNDULA, 2016). Para Zaluar (2017, p. 11), "nunca esteve tão claro o fracasso das políticas públicas de segurança no Brasil".

Segurança pública consiste em uma atividade desenvolvida pelo Estado com o objetivo de promover ações e oferecer estímulos positivos para que os cidadãos possam conviver em paz (CARDOSO, 2013). Sem embargo, no entender de Lima, Bueno e Mingardi (2016, p. 50), "a história recente da segurança pública no Brasil tem sido marcada por demandas acumuladas e mudanças incompletas", oportunizando a necessidade de se conduzir reformas estruturais no modelo de segurança pública e justiça criminal brasileiro, cujas respostas ao fenômeno da violência "têm se mostrado insuficientes para a promoção de uma sociedade segura e garantidora de direitos". Assim, com a perspectiva do desazo do Estado em prover segurança e ordenar a convivência social, o medo e as notícias de violência difundidos na coletividade estimulam a reação de indivíduos e grupos no sentido de sofisticar os recursos capazes de promover a defesa de suas vidas e de sua propriedade (CALDEIRA, 2000), justificando o deslocamento da capacidade de controle social e de manutenção da ordem para a iniciativa privada (RICARDO, 2006).

Nesse sentido, a disseminação dos serviços de segurança privada tem capturado a atenção da opinião pública e de especialistas (ZANETIC, 2010). Todavia, não obstante a vasta quantidade de textos acadêmicos relacionados tanto à área de segurança pública quanto à de segurança privada, poucos trabalhos remetem a contextos específicos, e a maioria das análises restringe-se a entendimentos genéricos e convencionais acerca do tema (SILVA, 2010). Por outro lado, desde a instituição efetiva dos serviços de segurança privada no Brasil, nos anos 1960, registra-se um intenso crescimento da demanda por tais serviços, inclusive pelo poder público, notadamente por órgãos da administração indireta (MARINS, 2010).

No âmbito específico do município do Rio de Janeiro, deve-se ponderar uma situação singular, pois como assevera Huggins (2010), o nível de belicosidade, de mortes e danos em virtude dos confrontos entre forças policiais e crime organizado pode apenas ser comparado a países que vivem em declarada guerra civil, o que não evidencia o caráter de uma política factual de controle social, mas antes tipifica uma guerra ao crime (CANO, 1997). Se "os homicídios no Brasil representam uma questão nacional de saúde pública, sendo a principal causa de morte de jovens" (CARDOSO et al., 2016, p. 1278), no Rio de Janeiro a disfunção nas políticas de segurança confere ao problema status de calamidade pública, com índices exorbitantes (LEITE, 2000). Em 2016, por exemplo, foram registrados 5.033 assassinatos no estado do Rio de Janeiro, sendo que os roubos de cargas, os assaltos a pedestres e os roubos de veículos foram os maiores já verificados desde o início da série histórica, em 1991 (HERINGER \& MARINATTO, 2017). 
No parecer de Freier (2016), até o presente momento, nenhuma política coerente de segurança pública foi levada a termo no Rio de Janeiro: a cooperação entre a polícia civil (investigativa) e a polícia militar (ostensiva) é insignificante; a polícia militar continua a seguir padrões marciais tradicionais de invasão, combate e eliminação; a brutalidade policial conta com métodos extralegais para combater o tráfico de drogas, mas também para extorquir a classe média e para reforçar a opressão da classe baixa; e as camadas sociais mais pobres estão entregues ao jugo de facções criminosas, às quais, ironicamente, precisam recorrer para obter proteção. Segundo o autor, os espaços públicos no Rio de Janeiro são caracterizados pela violência, pelo risco e pela privatização da segurança, a qual pode ser predicamentada ou como empreendimento clandestino, ou como setor institucionalizado e legalmente estruturado, que vem prosperando há décadas. Curiosamente, como notam Adorno e Pasinato (2010, p. 52), "permanecem indistintas as fronteiras dos interesses privados e (...) da segurança pública, devido, em grande parte, à extraordinária expansão do mercado privado à testa do qual não raro se encontram policiais civis e militares".

O objetivo da presente pesquisa consistiu em identificar de que forma, no município do Rio de Janeiro, a deficiência das políticas públicas de segurança influencia o setor privado de segurança. Para cumpri-lo, estruturou-se o artigo em três seções, além desta introdução e das considerações conclusivas. Na primeira delas, se interpresa uma revisão da literatura acadêmica sobre os temas de interesse do estudo. A seguir, esmiudam-se os procedimentos metodológicos para o cumprimento da etapa empírica do trabalho. Posteriormente, representam-se os resultados obtidos a partir da investigação no campo, que confiou em entrevistas semiestruturadas realizadas com informanteschaves do setor perquirido.

\section{MATERIAIS E MÉTODOS}

A parte empírica da presente investigação desenvolveu-se a partir de estudo qualitativo cumprido através do protocolo de entrevistas semiestruturadas realizadas junto a cinco informanteschaves, que formaram uma amostra intencional selecionada por critérios de tipicidade (PATTON, 1990). Informantes-chaves são caracterizados como indivíduos cujo conhecimento específico associado a contextos particulares, e cuja expertise relacionada a temas relevantes para a pesquisa em questão se revelam raros, significativos e capazes de propiciar informações fecundas (JOHNSON et al., 2007). Em virtude das peculiaridades de tais sujeitos, não se costuma determinar previamente um quantitativo ideal para a amostra da pesquisa, embora Creswell (1998) registre estudos baseados em informantes-chaves com amostras que reuniram desde um único até mais de uma centena de sujeitos. Pesquisas envolvendo informantes-chaves vêm sendo largamente utilizadas em estudos acadêmicos que abordam temas variados em segurança pública (por exemplo: DANG, 2015; KING, 2014; McGREGOR, 2016).

Tendo por base que a violência no Brasil possui diversas causas, sendo as principais relacionadas aos problemas sociais (SPANIOL, 2016). objetivou-se através das entrevistas obter posicionamentos diversos relacionados ao contexto da segurança pública e sua relação com o setor de segurança privada. Para tanto, pode-se considerar que a amostra de sujeitos relacionada na pesquisa atendeu ao objetivo traçado e permitiu traçar um panorama sobre a segurança privada e como se relaciona com o setor público. Importa ressaltar que não seria prudente versar sobre a exaustão de um tema tão complexo, uma vez que sempre haverá opiniões divergentes acerca da matéria, de forma que, mesmo que se controle todas as causas, em consonância com Spaniol (op. cit.), a complexidade do objeto de estudo não permitirá dar solução unívoca a todas elas, sem que a solução se integre novamente ao conjunto de causas. 
Os três primeiros informantes deste estudo são dirigentes de diferentes empresas de médio porte do ramo de segurança privada, localizadas no município do Rio de Janeiro - mais especificamente ligadas à área de segurança patrimonial e vigilância. No Rio de Janeiro, assim como nos demais estados da região Sudeste, observa-se a maior concentração de empresas de segurança privada do país, mas também uma maior pulverização do mercado - com quantidade expressiva de empresas de pequeno e médio porte - diferentemente do que ocorre no Nordeste, por exemplo, em que se verifica pronunciada concentração do mercado em poder de grandes empresas (CARDOSO et al., 2016). Assim, o informante I01 é diretor financeiro da empresa Alfa, enquanto I02 é diretor operacional da empresa Beta, e I03 é presidente da empresa Delta. O informante I04 integra a área de segurança dentro da administração pública do estado, sendo um oficial de alto escalão da Polícia Militar do Rio de Janeiro. Por fim, o sujeito I05 é presidente de uma organização privada que oferece serviços de treinamento em combate e defesa pessoal para civis, militares e forças policiais no Rio de Janeiro, em outras brasileiras e outros países, tendo capacitado forças armadas e de segurança, tais como fuzileiros navais, guardas municipais, policiais civis e militares.

A coleta de dados junto aos informantes-chaves contou com entrevistas pessoais semiestruturadas realizadas presencialmente (BISOL, 2012; JANSEN, 2010). As interlocuções com os dirigentes das empresas de segurança foram consumadas em suas próprias organizações. A entrevista com o informante-chave I04 foi efetuada em sua residência, enquanto a audiência com I05 ocorreu em um centro de treinamento. Em média, cada entrevista estendeu-se por 40 minutos, ao longo dos quais foram explorados dois principais tópicos de investigação propostos por Huggins (2010), bem como alguns de seus possíveis desdobramentos: (1) os processos institucionais que aquiescem e integralizam o controle social da população pelo Estado; e (2) a influência do setor privado na mercantilização da segurança pública (no caso particular do Rio de Janeiro).

Os dados obtidos foram gravados em áudio e/ou transcritos, e seu tratamento valeu-se da técnica da análise de conteúdo (CÂMARA, 2013; MOZZATO \& GRZYBOVSKI, 2011), submetendo-lhes a um procedimento triplo: (1) pré-análise por meio de leitura crítica; (2) exploração do material e avaliação do conteúdo dos trechos selecionados; e (3) classificação de termos e ideias com agrupamento em categorias predefinidas (FLICK, 2009). Para a representação de resultados, recorreu-se à análise interparticipante, ressaltando-se as falas mais relevantes dos informantes-chaves e desenvolvendo comentários para edificar um diálogo com os trechos mais significativos (VERGARA, 2012).

Como principais limitações metodológicas da investigação, destacam-se dois vieses cognitivos demonstrados pelos informantes-chaves em suas falas. Em primeiro lugar, conforme Zanetic (2010) e Leite (2014), os sujeitos podem ter suas percepções de violência e segurança deturpadas pela posição institucional que ocupam na cartografia social de uma cidade tão marcada pela criminalidade. Segundo, consoante Huggins (2010), em função da carência de dados científicos a respeito dos temas em exame, os depoimentos de alguns sujeitos remetem a estatísticas geradas pelas próprias forças policiais, que podem não ser consideradas fidedignas, devido ao infausto envolvimento dos agentes da lei no cometimento de delitos, fazendo com que determinados fatos sejam documentados erroneamente. 


\section{REVISÃO DE LITERATURA}

\section{- Contexto social e econômico da segurança privada}

No âmbito internacional, os serviços privados de segurança passaram a se expandir de forma mais significativa a partir dos anos 1960, estimulados por mudanças importantes nas dinâmicas socioeconômicas no mundo ocidental, em especial nos grandes centros urbanos (SOUTH, 1994; ZANETIC, 2010). O setor da segurança privada emerge, segundo Cardoso (2011), como herança da quebra do Estado de bem-estar e da ascensão de movimentos como o neoliberalismo e a globalização. Zanetic (op. cit.) identifica as principais causas dessa expansão como: o incentivo econômico e o espaço legal para o policiamento corporativo; o surgimento e a disseminação das "propriedades privadas em massa", também denominadas "espaços semi-públicos"; o crescimento real da criminalidade decorrente do aumento da distância entre as classes sócias, e, por conseguinte, a avultação da sensação de insegurança; e outros fatores secundários aos anteriores, tais como a pressão das companhias de seguros sobre seus clientes para a contratação de serviços especializados de proteção.

No Brasil, a institucionalização da segurança privada decorreu da exasperação do autoritarismo que fundeava o regime de exceção desinente do golpe militar de 1964 (CORTES, 2004). Com os incentivos ao setor privado de segurança, o governo visava conter a onda de assaltos às instituições financeiras. Agentes privados passaram a atuar como corresponsáveis pela manutenção da segurança do Estado, e os roubos a banco foram enquadrados na Lei de Segurança Nacional (HERINGER, 1992; SILVA, 1992). A partir de então, três aspectos podem ser apontados como impulsionadores da ampliação do mercado brasileiro de segurança: (1) a especialização do crime e o crescimento da violência; (2) a midiatização da violência e o aumento da insegurança social; e (3) as mudanças na utilização do espaço urbano e na circulação da população nas grandes cidades (ZANETIC, 2010).

Atualmente, em grande parte das nações ocidentais, o contingente de vigilantes privados supera, em muito, o número de policiais, formando um verdadeiro exército de guardas privados e veículos de segurança patrimonial (CARDOSO, 2011). Outrossim, com a dinâmica mercadológica atual, cada vez mais os serviços de segurança pública tendem a ser substituídos pelos privados, que oferecem, além de uma maior capacidade de adaptação - pois não estão sujeitos a procedimentos institucionalizados -, uma maior estabilidade e consequentemente, uma sensação superior de segurança (ZANETIC, 2010).

Dois processos políticos gradativamente orientaram a estruturação socioeconômica da indústria de segurança (CARDOSO, 2011; ZANETIC, 2010): a centralização do poder político pela consolidação do Estado-Nação; e o avanço do liberalismo como doutrina hegemônica. Desse modo, aqueles que podem pagar para suprir as lacunas deixadas pelo Estado em atividades essenciais como a segurança, não hesitam em fazê-lo. Por conseguinte, o Estado abre mão de suas prerrogativas, antes exclusivas, para investidas da iniciativa privada, que dilata sua participação no setor. Assim, aparentemente, ao permitir a participação do setor privado em serviços públicos fundamentais, o Estado passou a sucatear tais serviços.

Nesse sentido, em consonância com Bayley e Shearing (2001), a amplificação do mercado da segurança privada parece ter emergido entrelaçada ao mesmo contexto em que se dá o crescimento do crime, da violência e da sensação de insegurança, em grande parte proveniente de uma política de segurança pública deficiente. Com o advento do capitalismo globalizado, a hipervalorização da sensação de segurança e proteção dá lugar à liberdade de mercado, em que a 
segurança torna-se uma mercadoria, que o consumidor deve ser capaz de assegurar por sua própria capacidade (CASTEL, 2005). Assim, aqueles que puderem optar pela segurança privada não se contentarão com a segurança patrimonial, de modo que investirão também na proteção de suas residências e de outros locais pelos quais transitam, estabelecendo cartografias urbanas segregativas por meio de shoppings, clubes e condomínios fechados, nos quais é possível manter a segurança em função do distanciamento do indesejável, do intruso, mesmo que ele não tenha cometido ato ilícito, bastando sua presença para gerar o inevitável mal estar da insegurança e do medo (CARDOSO, 2011).

A complexa demanda por segurança revela também uma realidade distinta da visão comumente compartilhada acerca do setor. Apesar da ampla concentração dos investimentos em segurança nos setores mais abastados da população, pode-se notar que também há uma presença importante dos mais pobres como actantes sociais que utilizam, em alguma medida, recursos para sua proteção, como grades, trancas e alarmes, e mesmo nos bairros periféricos podem ser encontrados condomínios fechados - ou mesmo ruas ilegalmente obstruídas - bem como pessoal remunerado para fazer ronda e vigilância, demonstrando o caráter amplo que a adesão à busca por recursos de proteção tomou em grandes centros, evidenciando o caráter de complementaridade entre o privado e o público na segurança (ZANETIC, 2010).

Diante desse quadro, de acordo com Marins (2010), hodiernamente a atividade de segurança privada pode-se desdobrar entre os segmentos de: (a) vigilância patrimonial, ou preservação de bens e prevenção de riscos decorrentes de ações criminosas; (b) segurança orgânica, que remete a organizações que, ao invés de contratar serviços especializados de empresas de proteção, constituem seus próprios organismos de segurança; (c) segurança pessoal, que envolve acompanhamento e proteção de empresários, políticos etc.; (d) cursos de treinamento e qualificação de vigilantes; (e) escolta armada, ou acompanhamento motorizado e armado de bens e/ou pessoas; e (f) transporte de valores. Além dos serviços de vigilância e de segurança interna de empresas e instituições, pode-se acrescentar ao setor o aluguel e a venda de sistemas e equipamentos de prevenção e de combate ao crime, como câmeras e monitores, cercas, alarmes, blindagens, uniformes e armamentos (PAIXÃO, 1991).

\section{- A institucionalização da segurança privada}

$\mathrm{Na}$ apreciação de Zanetic (2010), a expansão dos serviços particulares de proteção traz à tona importantes questões relativas à responsabilidade do Estado sobre a segurança. Como assevera Ricardo (2006), é possível verificar na produção científica brasileira sobre o tema uma transformação gradual no enfoque dado à questão da expansão da segurança privada. Inicialmente, observa-se uma tendência em enfatizar a oposição entre o Estado democrático de direito e a ideia de Estado moderno com os serviços privados de segurança, havendo uma preocupação com um projeto de sociedade em que empresas privadas exploram uma atividade com monopólio estatal.

Paulatinamente, tal concepção cede espaço para a compreensão de que se trata de um setor de atividade econômica, com especificidades importantes o suficiente para ensejar mecanismos efetivos de regramento e controle, além de constituir uma atividade complementar à segurança pública, segundo a ideia de que a segurança privada só não será contrária à democracia se for pormenorizadamente regulamentada, fiscalizada e controlada, de forma que, conforme Spaniol (2016) o monopólio estatal da violência não significa apenas o uso dela com exclusividade, mas, também, o "monopólio" de prescrevê-la e de interditá-la. 
Nesse contexto, Zanetic (2010) pondera que o grande problema do setor de segurança privada no Brasil reside na fragilidade dos mecanismos de controle da atividade, a cargo da Delegacia de Controle da Segurança Privada (DCSP) e das delegacias estaduais correspondentes. Contudo, além dos poucos recursos dispensados para essa finalidade serem subaproveitados, a dificuldade se agrava pelo processo de expansão do setor, que age como mais uma barreira para a necessidade de regulamentação. Outra questão abarca a precariedade da fiscalização dos vigilantes, sujeitos a poucas e simples exigências legais, como ter bons antecedentes e receber aulas elementares de legislação e tiro, o que contribui para seu envolvimento em confrontos letais (KAHN, 1999). Consequentemente, a falta de uma regulação efetiva e específica, e a carência de uma fiscalização eficaz acabou transformando a segurança privada em um setor problemático no país (CARDOSO, 2011).

Não obstante, como testifica Zanetic (2010), no Brasil, bem como em diversos outros países, o modelo regulatório específico dos serviços de segurança é conduzido por órgãos governamentais da área de Justiça, mais especificamente pelo Ministério da Justiça, por intermédio do Departamento de Polícia Federal. O modelo prevalecente encontra respaldo nos modelos regulatórios existentes para o setor em diversas regiões e contextos diferenciados, em linha com o que se encontra na literatura internacional. $\mathrm{O}$ autor argumenta que a Polícia Federal sequer dispõe de um cadastro atualizado das empresas e das autorizações emitidas para os vigilantes, que lhe permita exercer suas atribuições de monitoramento. Já para Ricardo (2006), essa produção de informações tem caráter artesanal, o que dificulta seu planejamento e gestão. Além dessa limitação, não há recursos humanos e materiais suficientes para realizar as atividades de fiscalização e controle em todo o território nacional, e daí transcorre uma transferência parcial para as Secretarias Estaduais de Segurança Pública da responsabilidade pela fiscalização da segurança privada, por meio de convênios ou acordos informais.

Com o progressivo aumento da criminalidade e da violência, no Brasil, assim como na maioria dos países ocidentais, o discurso de "controle do crime" foi gradualmente substituído pelo discurso da "guerra contra o crime", fortalecendo no imaginário dos cidadãos e da polícia a ideia do perigo iminente e da necessidade de mobilização máxima de esforços para derrotar aquilo que provoca tais circunstâncias (PONCIONI, 2005).

Nesse contexto, como analisa Huggins (2010), além do sistema oficial de controle social da população, é preciso levar em conta dois processos institucionais aparentemente contraditórios. Por um lado, a centralização e a militarização da polícia profissional, e, por outro, a privatização e a descentralização do controle social repressivo. Enquanto uma parte do sistema de controle social tornou-se mais centralmente controlada e militarmente organizada, outra parte tem se tornado cada vez mais mercantilizada e voltada contra a população considerada problemática (DAVIS, 1992), e cada processo contribui de forma distinta para mascarar o papel do Estado na repressão.

Os antigos modelos adotados para combater a criminalidade não se mostram eficientes para lidar com as diferenças e incertezas que caracterizam as cidades contemporâneas, com suas ambivalências e contradições, exigindo, portanto, novas abordagens de governança interativa, baseadas em um diálogo profícuo entre governo e sociedade civil (FREY, 2004). Para Soares (2003), é crucial reformar as estruturas sociais, em benefício da justiça social, impondo uma inflexão nas desigualdades, expandindo a integração à cidadania e radicalizando a democracia. Zaluar (2017, p. 11) acrescenta que "o que melhor explica o crime e a violência não é a pobreza, é a oposição ao estado democrático de direito". 
Em suma, Frey e Czajkowski (2005) apregoam que se deve exigir das instituições públicas formas inovadoras de lidar com a diversidade com que se apresenta a violência, uma vez que as tradicionais formas de combater a criminalidade atingiram o ponto da exaustão. Por outro lado, é indispensável e urgente interceptar as dinâmicas geradoras da violência, para salvar vidas, hoje. Nesse âmbito, pode-se abordar a segurança privada como serviço que pretende suprir a deficiência do Estado em prover segurança aos cidadãos, ao mesmo tempo em que uma indistinção entre público e privado tende para a resolução privada dos conflitos públicos (CUBAS, 2005). Todavia, ainda que os serviços de segurança privada ganhem espaço, persiste o entendimento de que há complementariedade entre os serviços de segurança pública e privada. Desde que haja mecanismos de controle sobre os segundos, é possível conceber segurança provida por actantes públicos e privados (RICARDO, 2006).

Assoma daí o entendimento de que profissionais de segurança privada não se acham balizados, como aqueles da segurança pública, por rotinas, regulamentos e órgãos de controle, sendo a contenção das ameaças sofridas efetivamente ou apenas percebidas pelos clientes que compram o serviço, mais importante que garantir a segurança e a ordem sociais por princípios democráticos (PAIXÃO, 1991). Em contrapartida, retorna-se à tese da complementariedade, pela qual a segurança privada pode constituir uma força auxiliar da polícia na manutenção da ordem pública, liberando-a de tarefas que não são suas atribuições diretas, como vigilância patrimonial, segurança pessoal, transporte de valores, e contribuindo para que as polícias possam trabalhar diretamente na prevenção e controle da criminalidade (HERINGER, 1992).

No parecer de Zanetic (2010), demandas distintas fundam o crescimento da segurança privada e, caso o setor tenha sua regulamentação efetivada, será um serviço complementar à segurança pública. A própria administração pública constitui uma das principais responsáveis pelo incremento da atividade de segurança privada (MARINS, 2010). Ricardo (2006) discorre acerca da institucionalização progressiva dos serviços de segurança privada diante de uma aposta maior na resolução privada das questões públicas, ficando de lado a alternativa de investir e melhorar o aparato de segurança pública, que é ainda uma das funções primordiais do Estado. Portanto, o termo "institucionalizar a segurança privada", entendido de forma não literal - ao passo que efetivamente não o poderia ser por infringência à norma constitucional - deriva da utilização cada vez maior do aparato privado como forma de suplantar as debilidades da segurança pública torna-o quase parte integrante do setor de segurança estatal. À guisa de ilustração, recentes pesquisas provenientes da Federação Nacional das Empresas de Segurança e Transportes de Valores (Fenavist), apontam o poder público como maior contratante do mercado, utilizando cerca de $40 \%$ dos vigilantes (MARINS, op. cit.).

\section{- O problema da segurança pública no município do Rio de Janeiro}

Como recorda Soares (2003), a questão da segurança é parte não apenas das preocupações federais, mas também dos municípios e governo estadual. Na transição do regime militar brasileiro para a democracia, em meados dos anos 1980, todas as instituições públicas passaram por uma revisão e reajuste ao novo momento, com exceção da polícia, que não contou com projetos políticos capazes de adequá-la à nova realidade. No Rio de Janeiro, a progressiva deterioração das condições sociopolíticas e econômicas exacerbou a violência urbana, que teve seu ápice na década de 1990. O Rio de Janeiro adquiriu o perfil de uma cidade violenta e, com a escalada da violência policial, a cidade foi dominada pela "metáfora da guerra" (LEITE, 2000). Há exatas duas décadas, a gravidade do quadro foi assim expressa por Cano (1997, p. 19): "No Rio de Janeiro, por exemplo, a polícia 
mata tantos civis anualmente quanto o conjunto das forças policiais dos Estados Unidos, embora a população do Rio de Janeiro seja de 5,5 milhões e a dos Estados Unidos de mais de 250 milhões".

A crise nas instituições públicas e a desigualdade social, aliadas ao crescimento da violência urbana, ocasionam uma segregação do espaço público nas grandes cidades (AMARAL, 2010), e com o Rio de Janeiro o processo foi potencializado. Canclini (2003, p. 163) discorre acerca desse processo de decomposição do espaço urbano, onde a elite social se afasta do convívio com outros grupos: "seu peculiar modo de exercer a cidadania consiste em isolar-se da conflituosidade urbana mediante a privatização de espaços supervigiados".

O vácuo da presença estatal, sobretudo nos bairros de infra-estrutura mais precária e de menor renda da população, acarreta não apenas um acirramento dos problemas sociais, mas representa solo fértil para o alastramento da violência, e para a apropriação do capital humano e social em tais comunidades em favor dos interesses do crime organizado (FREY \& CZAJKOWSKI, 2005). Sob essa perspectiva, conforme acautela Amaral (2010), a origem do crime é associada às periferias, e os criminosos são vistos como pessoas gestadas nesses espaços marginais. $\mathrm{O}$ autor revela ainda que, em função de sua configuração espacial, "o Rio de Janeiro apresenta uma situação singular. Sua periferia não se encontra nas margens dos aglomerados urbanos, mas inserida nesses, através da formação das favelas nos diversos morros", permitindo que a desigualdade seja "visível em vários pontos da cidade, sendo ainda mais ostensiva na zona sul carioca, onde residem as classes mais altas" (op. cit., p. 35).

A partir dessa ordenação demográfica particular, define-se uma separação entre o asfalto e a favela. $\mathrm{O}$ asfalto é povoado pelas classes média e alta, pessoas percebidas pela polícia como cidadãos que merecem a proteção do Estado, porém tornados prisioneiros em suas próprias casas, ameaçados pela população da favela, onde os moradores fazem jus apenas a uma subcidadania (LEITE, 2000). Para Soares (2003), tal mapeamento não é subjetivo, e o medo da sociedade não pode ser classificado como ilusório ou fruto de manipulação midiática. De fato, o quadro de insegurança na cidade do Rio de Janeiro é extraordinariamente grave, por diferentes razões, dentre as quais destacam-se três questões determinantes.

Em primeiro lugar, "a magnitude das taxas de criminalidade e a intensidade da violência envolvida" (SOARES, 2003, p. 19), cuja dimensão pode ser apreendida quando se tem em vista o fato de que, segundo o Atlas da Violência 2016 (CERQUEIRA et al., 2016), o Brasil lidera em número de homicídios no mundo (em 2014 foram 59.627 pessoas mortas, tendo como fonte os registros do Ministério da Saúde) e que, nesse contexto, figura o Rio de Janeiro com uma taxa de 25,4 vítimas por 100 mil habitantes, valor próximo a média nacional de 25,7 vítimas/100.000 habitantes (PROVENZA et. al, 2017).

Em segunda instância, no Rio de Janeiro encontra-se majorada a exclusão de parcelas significativas da sociedade, que permanecem sem acesso a benefícios elementares propiciados pelo Estado democrático de direito, como liberdade de expressão e organização, e como o direito de ir e vir. De acordo com Silva e Silva (2012), por exemplo, um estudo do Instituto Brasileiro de Análises Sociais e Econômicas (Ibase) mostrou que comandantes de Unidades de Polícia Pacificadora (UPPs) coibiram em certas comunidades carentes os encontros sociais com preponderância de música funk, impuseram toque de recolher, e fixaram determinações comportamentais relativas ao falar, ao vestir e ao andar de cidadãos sob sua vigilância. Desta maneira, a fragmentação cultural possibilita a afirmação de outras identidades culturais que, ao exigirem reconhecimento no espaço público, podem transformar os choques interculturais em verdadeiras guerras comunitárias (SPANIOL, 2016). 
Em terceiro lugar, constata-se a degradação institucional vinculada ao crescimento da criminalidade: o crime se organiza e penetra cada vez mais nas instituições públicas, corrompendoas, e as práticas policiais continuam marcadas pelos estigmas de classe, raça e gênero, impingindo desconfiança à relação entre a polícia e os moradores, tanto por parte dos cidadãos quanto dos policiais (SILVA \& SILVA, 2012). O desenvolvimento das forças policiais, por sua vez, enfocando a especialização e o profissionalismo, é apontado como causa de seu próprio distanciamento em relação às comunidades atendidas, prestando serviços menos direcionados para a prevenção e mais para a reação aos delitos (OLIVEIRA, 2004). De maneira semelhante, aponta Spaniol (2016) para o fato de que, enquanto a população clama por ações imediatas e por mais segurança, principalmente em áreas de grandes concentrações urbanas, as autoridades responsáveis alegam dificuldades para enfrentar e amenizar o problema, atendo-se a questões pontuais em consequência de violências já ocorridas, e não trabalhando nos aspectos preventivos de novas ações de violência.

Por conseguinte, como assevera Soares (2003), quando as polícias são ineficientes, os direitos humanos sucumbem ao arbítrio e à violência. Com justeza, evidentemente, os problemas ligados à área de segurança pública são politizados, à medida que a legitimidade dos governos é predominantemente determinada por sua capacidade de manter a ordem e uma possível "paz pública". Em outras palavras, a presença ou a ausência do governo são avaliadas e mensuradas, no imaginário da população, pela capacidade de manter a ordem e a segurança pública (BARREIRA, 2004). Frey e Czajkowski (2005) acrescentam que, mesmo sendo a segurança pública responsabilidade primordial dos estados, é nos municípios que os problemas da violência são percebidos pelos cidadãos, colocando em xeque a legitimidade democrática de governos locais, que acabam por restringir sua atuação a lamentar a suposta inoperância ou ineficiência dos estados e da União no combate ao crime e à violência urbana.

No Brasil, os municípios não contam com forças policiais próprias, apenas com guardas civis - como a Guarda Municipal, no Rio de Janeiro -, em geral limitadas à proteção do patrimônio público e, portanto, só poderiam enfrentar a violência criminal e manter a ordem e a segurança pública com políticas preventivas de natureza não policial, ainda que sempre contando com a colaboração das polícias estaduais militar e civil (SOARES, 2003). Tal limitação poderia se converter em virtude, por intermédio de iniciativas criativas para a propositura de ações preventivas à violência. Conscientes de que a violência urbana decorre não somente do fortalecimento do crime organizado, mas de fatores como a exclusão social, o racismo, o desemprego, a exposição cotidiana dos jovens a infraestruturas e ambientes urbanos degradados, os governos municipais encontram-se diante do desafio de ampliar a participação pública nas políticas de segurança pública, visando conter o atual processo de cotidianização da violência urbana (FREY \& CZAJKOWSKI, 2005).

\section{RESULTADOS E DISCUSSÃO}

\section{- A segurança pública aos olhos da sociedade}

Atualmente, a violência urbana constitui um desassossego discutido profusamente, tanto pelos governantes, quanto pelos demais segmentos da sociedade, configurando-se há décadas como um dos fenômenos que mais angustiam os habitantes das grandes cidades brasileiras (ADORNO \& PASINATO, 2010). No Rio de Janeiro, a situação já enraizada da violência no cotidiano da população, aliada ao tratamento dado pela mídia ao crime violento - que espetaculariza os episódios de violência e consolida os estereótipos relacionados à criminalidade - contribui para o descrédito dos órgãos responsáveis pela segurança pública (ANDRADE, 2013). Nesse contexto, foi valorizado 
na fala dos informantes-chaves o impacto da mídia sobre a percepção dos serviços prestados pelos órgãos de segurança pública:

- O nível de credibilidade da segurança pública no Rio de Janeiro sempre foi muito baixo, mas hoje eu vejo ele mais baixo ainda. Há pouco tempo, no programa da Fátima Bernardes teve um quadro em que a pessoa se via em um dilema entre salvar a vida de um idoso, uma criança, um traficante ou um policial. No final, o policial acabou sendo salvo depois do traficante (...). Isso já mostra um pouco da influência da Globo e da mídia em geral. Se a gente fosse fazer uma pesquisa séria, não sei se esse seria o resultado, mas pra mídia o que importa é vender (...) ela sempre vai expor o lado do policial corrupto, que é o que vende. (...) Se você for olhar uma pesquisa histórica, no final vai dar sempre muito baixo o nível de credibilidade da polícia e dos demais órgãos de segurança pública. (I03)

- Existe uma coisa chamada "sensação de segurança" e tem a "verdadeira segurança”. A verdadeira segurança se baseia em números. Há uns três anos atrás, se não me engano, porque não estou atualizado a respeito dos números, a cidade mais violenta do Brasil a cada cem mil habitantes era Arianópolis, no Ceará, que ninguém nunca ouviu falar. Só que a mídia coloca o quê? Rio de Janeiro, São Paulo (...) A mídia vive de dinheiro, e quem gera dinheiro são as capitais (...) então algumas cidades de interior, muito violentas, existem para os números, mas acabam não existindo para o público. (...) A verdadeira violência baseia-se em números, e é daí que nós temos que partir. (I05)

- A situação hoje no Rio de Janeiro tá muito complicada (...) a mídia também fortalece muito isso. Pra você ter uma ideia, a Polícia Militar deve ter em torno de quarenta mil homens e a Civil algo em torno de nove, ou dez mil homens. Eu posso lhe afiançar que, desses homens, a grande maioria são honestos e querem fazer um bom trabalho, $10 \%$ no máximo ou menos são de má índole (...) mas o que vende jornal são esses $10 \%$ (...)é disso que a sociedade quer saber. (I02)

De acordo com os sujeitos da pesquisa, portanto, verifica-se uma relação direta entre a veiculação de notícias que envolvem aspectos de violência e criminalidade, e o crescimento do descrédito do setor de segurança pública. Outra questão que emergiu a partir das falas dos informantes evidenciou que parte do menoscabo pelas instituições de segurança pública provém da atuação ostensiva na prevenção dos delitos, uma das funções exercidas pela segurança pública por intermédio da Polícia Militar:

- A polícia, tanto a preventiva (Militar) quanto a repressiva (Civil) são em geral muito mal avaliadas pela população, mas isso acaba refletindo mais na Polícia Militar que na Civil, por ela ser ostensiva (...) acaba ficando em evidência quando acontece um crime porque é, em geral, a primeira a agir. (I03)

- Às vezes, é só uma questão de trocar a camisa (...) as pessoas já estão acostumadas com a ideia da polícia como órgão opressor. Agora você vê, trocaram para aquele Lagoa Presente, Lapa Presente, as pessoas tão adorando. Se, por exemplo, você colocasse na Lagoa ou na Lapa um Policial Militar mesmo atuando, na mesma função, não sei se o resultado seria o mesmo. (I02) 
- O grande problema da polícia (principalmente a Militar) é que ela é aquela que está na rua fazendo com que a lei e a ordem sejam cumpridas. Então, na maioria das vezes, muitas pessoas não gostam da presença da polícia em virtude de ter de ser parado na blitz, ter de mostrar documento, acham isso um constrangimento (...) outra coisa que pesa é o fato de estar fardado. Isso põe o policial em evidência como coator imediato de ações ilegais, por menores que sejam. (I04)

Contrastando com a última fala, deve-se remeter ao fato de que a alta taxa de letalidade e de ações violentas praticadas por autoridades policiais no Rio de Janeiro (HUGGINS, 2010) também pode ser considerado um fator crucial para o atual desprestígio dos órgãos de segurança pública no município. Assim, por vezes, o constrangimento relatado pode tomar a forma do receio de uma abordagem violenta, principalmente em áreas associadas às classes menos favorecidas (SILVA \& SILVA, 2012), onde a ação policial não costuma diferenciar criminosos e moradores de favelas. Conforme asseveram Silva e Silva (2012), toda sociedade é uma estrutura de poder em que prevalece a imposição de alguns sobre os demais. Neste caso a imposição é, em geral, exercida pelos órgãos de segurança pública que, na maioria das vezes, não o fazem por conta própria, mas seguindo um sistema bramoso e segregacionista, outorgado pelos efetivos detentores do poder (SIAFAKA, 2016).

\section{- A interação entre público e privado no âmbito da segurança}

A presença dos serviços privados de segurança tornou-se mais palpável desde o início do século XX, por ocasião de fatores como a disseminação das propriedades privadas em massa, a medrança na sensação de insegurança e a pressão das companhias de seguros sobre seus clientes (ZANETIC, 2010). A partir de tal contexto, como se viu, recrudesce o processo de mudança estrutural no papel do poder público, defendendo-se o compartilhamento de prerrogativas até então exclusivas do Estado com outros atores sociais, principalmente com o setor privado, em nome de um possível fortalecimento da sociedade civil, com uma maior participação da mesma na Administração Pública (CARDOSO, 2011; MARINS, 2010).

Nesse sentido, retornando-se às falas dos sujeitos de pesquisa, depreende-se que no âmbito da segurança na cidade do Rio de Janeiro aparentemente não há integração do setor público com o setor privado. Por exemplo, delitos reportados por empresas de segurança privada raramente despertam a atenção do setor público - com exceção dos casos de maior repercussão -, o qual, quando interessado, limita-se a requisitar imagens de câmeras de segurança para tentar solucionar aspectos relacionados à autoria e materialidade do delito:

- A união entre o setor público e o privado nesse aspecto é uma ilusão. O que acontece é que as pessoas se sentem totalmente incomodadas com o fato da ineficiência da segurança pública e não entendem que ela existe para proteger a sociedade e não o indivíduo. (...) Elas têm objetivos diferentes, realizam tarefas diferentes e têm como objeto VIPS, dignatários, e objetos de proteção diferentes (...) não tem como falar em integração entre a segurança pública e privada. (I05)

- Não existe uma interação da forma ideal (...) o que o empresariado da segurança pode fazer pra ajudar a segurança pública, ele está disposto a fazer, mas muitas vezes não há interesse do Estado nessa interação. (I02)

- Deveria existir uma interação maior entre esses setores, como acontece em outros países. Se você, por exemplo, coloca um alarme numa casa nos Estados Unidos, 
Alemanha, França, ele está diretamente ligado aos órgãos de segurança pública. A polícia aqui não quer isso ligado a ela, porque vai gerar demanda (...) E como tem a empresa privada, ela acha que é problema da empresa reprimir aquele delito (...) $O$ que existe com relação a integração é que, quando ocorre um crime e o poder público tem interesse em apurar, ele vem pedir as imagens das câmeras de segurança, ai nós ou mesmo o próprio cliente cede as imagens. (I03)

Do que foi relatado no último trecho, pode-se inferir que parece haver, na prática, negligência por parte da autoridade policial, em razão do desvio na preocupação principal da prestação do serviço que incumbe exclusivamente ao Estado - atuar na repressão ao crime (PONCIONI, 2005). Desse modo, em determinadas situações, a atuação repressiva recai sobre o setor privado, que não é regularmente incumbido de realizar tal função, o qual deve apenas atuar auxiliando a ação preventiva em ambientes fechados ou intramuros (RICARDO, 2006):

- Por exemplo, eu tenho um alarme em casa. Se o alarme soa, e a polícia é alertada por meio do vigilante que eu contratei para estar dentro daquele ambiente, eles em geral mandam ele mesmo resolver o problema, uma vez que ele recebe para isso (...) Eles entendem que, se a minha empresa tem um lucro pra trabalhar garantindo a segurança, ela que resolva o problema porque eles têm coisa mais importante a fazer, mas é na rua que está o problema. (I03)

Em contrapartida, consoante Ricardo (2006), pode-se considerar que a segurança privada figura como um parceiro júnior no negócio de policiamento, ajudando seu parceiro sênior (a polícia pública) na manutenção da paz. Assim, as instituições privadas podem atuar como auxiliar do poder público, de forma a prover segurança em espaços públicos, fechados e de grande circulação de pessoas, onde para que houvesse tutela do poder público demandar-se-ia grande contingente de agentes, o que causaria perdas no efetivo policial ostensivo presente em logradouros públicos, com vistas a prevenir a ocorrência de delitos:

- O emprego da segurança privada nos ambientes públicos fechados, por exemplo, é essencial, até por que não há efetivo (público) para cobrir essa demanda (...) até por que o poder público atua em prol da sociedade e não pode ficar em função de ambientes determinados. Então essa utilização da segurança privada em locais de grande concentração de pessoas é importantíssima. (I04)

- O emprego de uma segurança orgânica (privada) em ambientes públicos fechados seria muito importante (...) Você consegue ajudar o Estado agindo preventivamente (...) é muito mais fácil e eficaz, porque eles já conhecem o local, as entradas, a equipe e conseguem solucionar a maior parte dos problemas. (I05)

- É fundamental a atuação da segurança privada em locais como o metrô, por exemplo. (...) Isso poderia ser feito em outro espaços públicos fechados, não fossem certas vaidades (...) Existia um projeto piloto para implantar segurança privada para fazer tarefas dentro dos quartéis de Polícia Militar, inclusive de vigilância, mas acabou não indo pra frente (...) Pra mim, esses serviços poderiam muito bem ser terceirizados. Você vê, outro exemplo é o serviço de atendimento do 190. Você acha que valeria perder um policial só pra atender o telefone? (I02)

Em harmonia com as falas dos informantes-chaves - muitos dos quais patentearam nesse ponto seus próprios interesses -, outro fator igualmente importante refere-se ao custo de se manter 
um agente público policial designado para a única função de prover segurança em espaços determinados. Na opinião de Marins (2010), adicionalmente, a necessidade de modernização na prestação de serviços públicos mais parcimoniosos, a despeito dos inúmeros críticos, torna inexorável esse processo. Conforme destacado, a contratação de serviços privados de segurança requer menor investimento de recursos, além da desobrigação de estruturação do sistema de segurança, tarefa que seria delegada à empresa contratada.

- Serviço terceirizado de segurança é muito mais em conta que serviço público (...) se você fosse tomar conta de todos os espaços privados de convívio público com segurança pública iria demandar muito mais estrutura e dinheiro. (I03)

- Com emprego do serviço terceirizado de segurança, você provavelmente iria conseguir um preço muito mais em conta, em função da concorrência que acontece nas licitações pra terceirização desses serviços (I02)

\section{- O lado da demanda pela segurança privada}

Nos depoimentos dos sujeitos da pesquisa, constatou-se que, em determinadas situações subsiste certa carência de confiabilidade por parte dos contratantes dos serviços de segurança privada - o que pode ser explicado pela função eminentemente preventiva dos serviços -, bem como dos agentes de segurança contratados. Pela dificuldade na mensuração com relação à coação aos delitos - em decorrência da natureza preventiva do serviço contratado - parece haver a percepção de uma sensação de nimiedade por parte dos clientes:

- Os usuários desse serviço - por exemplo, nas universidades, os universitários - veem o vigilante como alguém que não serve para nada. Na verdade, toda força de segurança passa um pouco por isso. Se você passa na rua, por exemplo, e vê um policial dormindo, você logo pensa: "viu, não serve para nada” (...) Não há como mensurar, então se tem a sensação de que não serve para nada. (I03)

Como se viu anteriormente, em determinados casos, o agente de segurança se vê impossibilitado de agir - talvez até mesmo para proteger a vida do contratante. Em tais momentos, cresce a sensação de sobejidão da segurança privada. Muito embora haja uma expressiva prevenção de delitos por conta da contratação dos serviços de segurança, o contratante só irá imaginar que, naquele momento em que houve a conduta criminosa em face de seu estabelecimento, o serviço contratado não pôde atuar para proteger seu patrimônio:

- Houve um assalto a um cliente em que os criminosos entraram, amarraram o vigilante numa árvore e roubaram tudo. Qual a ideia que ficou para o cliente? Eu pago isso e não adiantou para nada. Ele não vai pensar que foi sorte só ter acontecido aquele em cinco anos (...) Da mesma forma, caso não aconteça nada, o cliente tem a sensação de que não precisa daquilo, mas na verdade, só não está acontecendo nada porque ele contratou o serviço de segurança privada (...) Então, a visão da segurança é sempre um peso, porque o usuário tem a sensação de que paga para nada, porque ela atua preventivamente. (I03)

Em contrapartida, registra-se nas falas dos informantes a percepção de que, mesmo com esse eventual sentimento de inutilidade, a credibilidade do agente de segurança privada em face dos usuários dos serviços costuma ser boa, muito porque - diferentemente do agente de segurança 
pública -, as representações mais usuais desses profissionais lhes caracterizam não como agente de autoridade, mas antes como prestador de serviços do estabelecimento:

- É diferente do policial. Primeiro, porque a mídia dá muito enfoque nos problemas do Estado e raramente se preocupa com os problemas de segurança privada. Isso gera uma menor desvalorização dos agentes. Depois, porque o vigilante tá ali pra proteger os clientes e o patrimônio, e se isso envolver se render, ele não vai ver problema nenhum nisso (...) o policial não, na maioria dos casos ele vai acabar reagindo, primeiro, pra proteger a própria vida (...) segundo, porque ele tem a tarefa de fazer se cumprir a lei e a ordem. (I05)

- É uma questão cultural (...) às vezes uma questão de trocar a camisa (...) de uma maneira geral, o ambiente em que eles (vigilantes) atuam favorece um melhor trabalho, diferente do policial, e, dessa forma, eles acabam sendo mais bem vistos (...) Com esse trabalho, eles acabam angariando o apoio da sociedade em geral, acabam angariando o apoio da mídia e as coisas acabam fluindo melhor. (I02)

Não obstante os pareceres dos sujeitos I02 e I05, há que se ressaltar que Ricardo (2006) estabelece uma relação direta de proporcionalidade entre o aumento no número de empresas irregulares de segurança e o crescimento da desvalorização dos agentes relacionados a tal setor. Dessa maneira, com a expansão das empresas ilegais - fato inclusive aludido nas falas dos informantes como prejudicial à expansão do mercado regular - torna-se inevitável, mesmo que em parte, a desvalorização do profissional de segurança privada em decorrência de ações abusivas relacionadas, na maioria dos casos, à intervenção de actantes ilegais. Deve-se altear, adicionalmente, que a questão da pertinência da segurança privada atrela-se estreitamente ao fator cultural - ligado ao contexto histórico de cada localidade (ZANETIC, 2010), de modo que, em certos países, mesmo com níveis baixos de criminalidade, registram-se investimentos vultuosos tanto em aparatos de proteção quanto na contratação de vigilantes:

- Isso é muito cultural (...) Nos Estados Unidos, pelos níveis de criminalidade que eles têm era para se ter metade do número de empresas de segurança privada, mas lá eles têm essa cultura de segurança (...) Aqui era pra se ter dez vezes mais empresas pelo nível de criminalidade, mas as pessoas não têm essa cultura. (I03)

- Não deixa de ser um aspecto cultural também (...) Nos Estados Unidos, todas as lojas têm serviço de segurança privada (...) e a maioria das casas também (...) O agente de segurança privada acaba sendo mais respeitado também, até porque, em certos casos, eles têm respaldo pra agir com poder de polícia. Então eu acredito que o aspecto da cultura influa muito aí também. (I01)

\section{CONCLUSÃO}

Os autores do presente artigo partilham da ideia de que se deve conceber a "segurança pública como um direito de todos, tal como define a Constituição, mas entendendo-o como um guarda-chuva que compreende a observância de garantias fundamentais" (LEMGRUBER, CANO \& MUSUMECI, 2017, p. 53). Infelizmente, como observa Freier (2016), as maiores cidades brasileiras facejam um ritmo vertiginoso de expansão da violência urbana e de eclosão das taxas de criminalidade, a ponto de, por exemplo, muitas organizações produtivas nacionais e estrangeiras terem desertado das áreas metropolitanas de municípios como Rio de Janeiro e de São Paulo, no 
intuito de escapar das crescentes ocorrências de furtos, roubos, sequestros e assassinatos. O autor defende que, para muitas empresas, a continuidade de suas atividades produtivas no Rio de Janeiro, especificamente, tem suas chances de consumação fadadas à implementação de estratégias de segurança envolvendo negociação com actantes sociais públicos e privados.

Nesse contexto, a pesquisa pautou-se pelo objetivo de identificar de que forma, no município do Rio de Janeiro, a deficiência das políticas públicas de segurança influencia o setor privado de segurança. Uma conclusão inicial baseia-se no fato de tal expansão admitir contextos particulares e motivos variáveis, de acordo com a região estudada. Os resultados alcançados também precisam ser contemplados à luz do entendimento de que a segurança pública dificilmente pode ser alcançada apenas por meio da ação repressiva do Estado, devendo antes passar, necessariamente, por políticas sociais efetivas, particularmente nas áreas de educação, saúde, emprego e saneamento (PROVENZA et. al., 2016), assim como pela melhoria da qualidade de vida no âmbito comunitário (FREY \& CZAJKOWSKI, 2005). O problema é mais complexo que parece.

Por um lado, um estudo recente conduzido pelo Escritório das Nações Unidas sobre Drogas e Crime revelou que o Brasil abriga $2,8 \%$ da população mundial, porém acumula $11 \%$ dos homicídios registrados em todo o planeta (LIMA, BUENO \& MINGARDI, 2016). Por outro, constitui uma tarefa desafiadora tratar de segurança pública "numa sociedade excludente e desigual como a sociedade brasileira, na qual há séculos se tem negado a uma parcela significativa da população o direito de acesso ao mínimo necessário para uma existência digna, independente e autônoma" (ALVES, 2017, p. 1394). Cabe salientar que, pelo Coeficiente de Gini - medida de desigualdade de distribuição de rendimentos amplamente utilizada em ciências sociais - o Rio de Janeiro, universo da presente pesquisa, é a cidade com o maior índice de desigualdade do hemisfério sul (FREIER, 2016).

Por intermédio do estudo de campo conduzido para a presente pesquisa, buscou-se obter informações mais específicas no contexto da cidade do Rio de Janeiro e sobre as singularidades do mercado. Assim sendo, foi possível identificar fatores que exercem influência sobre o segmento da segurança privada e concorrem para sua expansão - alguns dos quais não parecem ter sido abordados em investigações anteriores. Ficou patente, por exemplo, a relação de causalidade entre a espetacularização da violência e o crescimento do setor: com a cobertura midiática cingindo episódios aparatosos dos conflitos entre o poder público e o crime organizado no Rio de Janeiro, avoluma-se a sensação generalizada de insegurança.

Assim, apesar de não constituir um fator único ou isolado, a violência que se vê nos noticiários constitui um fator que contribui para a situação de insegurança atual. Apesar de constituir instrumento democrático, uma vez que possibilita acesso à informação, fator vital para a formação da opinião, a abordagem midiática da violência comumente privilegia o espetáculo em detrimento da discussão esclarecida dos problemas, o que por sua vez desencadeia uma reação de medo, que aporta para o irracional. Nesse contexto, talvez seja preciso "trabalhar com a cúpula das mídias, com a direção das emissoras e dos jornais, alertando para as consequências do que está sendo veiculado e mostrando a necessidade do contraponto, do espaço para o 'outro lado' para outras visões, narrativas e perspectivas” (LEMGRUBER, CANO \& MUSUMECI, 2017, p. 52).

Dentro dessa lógica, um público mais crítico seria menos vulnerável aos efeitos do discurso midiático e, consequentemente, poderia se dizer mais seguro (FLORES \& GREGORI, 2012). Por conseguinte, no contexto atual, cresce a demanda por alternativas privadas de segurança. Da mesma forma, de acordo com os informantes da pesquisa, a amplificação da presença ostensiva do efetivo policial nas ruas, contraditoriamente, produz um efeito semelhante. 
Uma questão recorrente nos relatos dos informantes envolveu o elevado custo dos serviços regularizados de segurança privada, frente à desregrada concorrência de empresas ilegais, fator que também exerce forte influência negativa sobre a expansão das empresas formais de segurança. Diante da falta de recursos para investir em proteção pessoal e patrimonial, em muitos casos opta-se por reduzir os custos contratando empresas irregulares, as quais frequentemente são prestadoras de serviços de portaria ou de limpeza que escalam seus funcionários para trabalhar como vigilantes (RICARDO, 2006). Aos olhos do contratante, parece um bom negócio, à medida que se consegue reduzir os custos e, ao mesmo tempo, transmitir uma maior sensação de segurança pela presença física do funcionário, mesmo que ele não esteja capacitado para aquela atribuição. A seguinte fala do sujeito I02 é emblemática com respeito a essa temática:

"A segurança privada é um ramo que fatura demais, mas a lucratividade é muito baixa (...) O custo do serviço é muito alto, então ela acaba custando muito caro pro contratante (...) então, a vontade do empresário em contratar é muito grande, mas na prática eu não tenho percebido uma expansão do mercado. Então, mesmo que haja necessidade de se ter a segurança, muitas vezes, por falta de recursos não há contratação (...) por exemplo num condomínio, com o aumento da inadimplência por causa da crise, o síndico, se vendo numa situação de corte de gastos, acaba substituindo o serviço de vigilância patrimonial do vigilante pelo porteiro. Porque pro grande público parece que é a mesma coisa. Então você consegue reduzir os gastos, porque o porteiro custa bem menos (...) isso acaba influenciando o nosso ramo, porque entram empresas descredenciadas com profissionais desqualificados (...) pras pessoas parece a mesma coisa, mas são serviços completamente distintos. (I02)

Por fim, conforme assevera Zanetic (2010), o fenômeno de surgimento e expansão dos serviços privados de segurança não pode se resumir à questão da falência da segurança pública, nem ser atribuído exclusivamente à suposta crise de legitimidade do Estado, antes se achando atrelado a múltiplos determinantes de ordem política, econômica, social e cultural.

Note-se que, no Brasil, o problema da segurança pública se tornou "um tema de profundo interesse nacional" (SOUZA \& MINAYO, 2017, p. 3). Abordar a questão com a seriedade correspondente significa trazê-la para o debate democrático de modo a contribuir para o desenvolvimento do país. De modo amplo, assim se pode descrever a relevância do trabalho, ao qual podem seguir-se novos esforços de pesquisa. Outros estudos poderiam abordar questões relativas ao mercado informal de segurança privada, aprofundando-se na questão de seu impacto na expansão do mercado regularizado. Da mesma forma, poder-se-ia abordar a relação do agente informal de segurança com o mercado, bem como a atuação do policial na segurança privada. Por fim, outro ponto que poderia servir de alicerce para novos estudos diz respeito aos custos relacionados ao setor de segurança privada, e que podem constituir grande impedimento à expansão do mercado regularizado.

Tomando por alicerce o estudo aqui apresentado, a respeito da temática da expansão do setor de segurança privada no Rio de Janeiro, novos esforços de pesquisa podem abordar questões relativas ao mercado informal de segurança privada, aprofundando-se na questão de seu impacto na expansão do mercado regularizado. Pode-se igualmente tratar da relação do agente informal de segurança com o mercado, bem como da atuação do policial na segurança privada. Outro ponto de partida para novas investigações poderia envolver os custos atinentes ao setor privado de segurança, que podem refrear a expansão do mercado regular. 


\section{REFERÊNCIAS}

ADORNO, S.; PASINATO, W. Violência e impunidade penal: da criminalidade detectada à criminalidade investigada. Dilemas: Revista de Estudos de Conflito e Controle Social, v. 3, n. 7, p. 51-84, jan.-mar. 2010.

ALVES, F. Segurança pública, cidadania e controle social. Revista de Artigos do $\mathbf{1}^{\mathbf{0}}$ Simpósio sobre Constitucionalismo, Democracia e Estado de Direito, v. 1, n. 1, p. 1383-1397, 2017.

BARREIRA, C. Em nome da lei e da ordem: a propósito da política de segurança pública. São Paulo em Perspectiva, v. 18, n. 1, p. 77-86, 2004.

BAYLEY, D.; SHEARING, C. The new structure of policing: description, conceptualization, and research agenda. Washington: National Institute of Justice, 2001.

BISOL, C. Estratégias de pesquisa em contextos de diversidade cultural: entrevistas de listagem livre entrevistas com informantes-chave e grupos focais. Estudo de Psicologia, v. 29, n. 1, p. 719s-726s, out.-dez. 2012.

CALDEIRA, T. Cidade de muros: crime, segregação e cidadania em São Paulo. São Paulo: Ed. 34/ Edusp, 2000.

CÂMARA, R. Análise de conteúdo: da teoria à prática em pesquisas sociais aplicadas às organizações. Gerais: Revista Interinstitucional de Psicologia, v. 6, n. 2, p. 179-191, 2013.

CANCLINI, N. A globalização imaginada. São Paulo: Iluminuras, 2003.

CANO, I. Letalidade da ação policial no Rio de Janeiro. Rio de Janeiro: Iser, 1997.

CARDOSO, B. Megaeventos esportivos e modernização tecnológica: planos e discursos sobre o legado em segurança pública. Horizontes Antropológicos, v. 19, n. 40, p. 119-148, 2013.

CARDOSO, C. A atuação das empresas de segurança privada no Brasil: investigação de casos encaminhados ao tribunal de justiça do Rio Grande do Sul. Dissertação de Mestrado apresentada ao Programa de Pós-Graduação em Ciências Criminais da Pontifícia Universidade Católica do Rio Grande do Sul. Orientação: Prof Dr Rodrigo Ghiringhelli de Azevedo. Porto Alegre: Pontifícia Universidade Católica do Rio Grande do Sul, 2011.

CARDOSO, F.; CECCHETTO, F.; CORRÊA, J.; SOUZA, T. Homicídios no Rio de Janeiro, Brasil: uma análise da violência letal. Ciência \& Saúde Coletiva, v. 21, n. 4, p. 1277-1288, abr. 2016.

CARVALHO, L.; ESPÍNDULA, D. Discussões em torno do referendo sobre o comércio de armas de fogo e munição na Folha de S. Paulo. Opinião Pública, v. 22, n. 2, p. 446-465, ago. 2016.

CASTEL, R. A insegurança social: o que é ser protegido? Petrópolis: Vozes, 2005.

CAVALCANTI, G. Crime custa US\$ 91,38 bilhões ao ano para o Brasil. O Globo, 3 de fevereiro de 2017. p. 12.

CERQUEIRA, D; FERREIRA, H.; LIMA, R.; BUENO, S.; HANASHIRO, O.; BATISTA, F.; NICOLATO, P. Atlas da violência 2016. Nota técnica. Fórum Brasileiro de Segurança Pública (FBSP). Rio de Janeiro: IPEA, 2016.

CORTES, V. A participação de policiais militares na segurança privada. Monografia apresentada ao Programa de Pós-Graduação em Políticas Públicas de Justiça Criminal e Segurança Pública da Universidade Federal Fluminense. Orientação: Prof Dr Roberto Kant de Lima. Niterói: UFF, 2004.

CRESWELL, J. W. Qualitative inquiry and research design: choosing among five traditions. Thousand Oaks: Sage, 1998.

CUBAS, V. Segurança privada: a exploração dos serviços de proteção e vigilância em São Paulo. São Paulo: Associação Editorial Humanitas, 2005. 
DANG, N. Know your rights and police misconduct: a case study of organizer's perceptions of community-based work. Dissertação de Mestrado apresentada à Escola de Serviço Social da California State University. Orientação: Prof ${ }^{a}$ Dr $^{\mathrm{a}}$ Nancy Meyer-Adams. Long Beach: California State University, 2015.

DAVIS, M. City of quartz: excavating the future in Los Angeles. New York: Vintage Books, 1992.

FLICK, U. Introdução à pesquisa qualitativa. São Paulo: Artmed, 2009.

FLORES, M.; GREGORI,M. Modernidade e mídia: Reflexões sobre a sensação de insegurança na sociedade da informação. Mídia e direitos da sociedade em Rede. Anais do Primeiro Congresso internacional de direito e contemporaneidade. Santa Maria, RS, 2012.

FREIER, A. Corporate security governance and the "intrinsic logic" of Rio de Janeiro and São Paulo. Colección, n. 26, p. 137-161, 2016.

FREY, K.; CZAJKOWSKI, S. O município e a segurança pública: o potencial da governança democrática urbana. Revista de Administração Pública, v. 39, n. 2, p. 297-325, 2005.

HERINGER, C.; MARINATTO, L. Homicídio doloso atinge o pior número no estado desde 2009. O Globo, 2 de fevereiro de 2017. p. 11.

HERINGER, R. A indústria da segurança privada no Rio de Janeiro. Dissertação de Mestrado apresentada ao Instituto Universitário de Pesquisas do Rio de Janeiro. Orientação: Prof ${ }^{a}$ Dr $^{a}$ Licia do Prado Valladares. Rio de Janeiro: IUPERJ, 1992.

HUGGINS, M. Violência urbana e privatização do policiamento no Brasil: uma mistura invisível. Caderno CRH, v. 23 , n. 60 , p. 541-558, 2010.

JANSEN, H. The logic of qualitative survey research and its position in the field of social research methods. Qualitative Social Research, v. 11, n. 2, p. 1-21, 2010.

JOHNSON, P.; BUEHRING, A.; CASSELL, C.; SYMON, G. Defining qualitative management research: an empirical investigation. Qualitative Research in Organizations and Management, v. 2, n. 1, p. 23-42, 2007.

KAHN, T. Cidades blindadas: ensaios de criminologia. São Paulo: Conjuntura Criminal, 2001.

KING, W. Organizational failure and the disbanding of local police agencies. Crime \& Delinquency, v. 60, n. 5, p. 667-692, 2014.

LEITE, M. Entre a "guerra" e a "paz": Unidades de Polícia Pacificadora e gestão de territórios de favela no Rio de Janeiro. Dilemas: Revista de Estudos de Conflitos e Controle Social, v. 7, n. 4, p. 625-642, out.-dez. 2014.

LEITE, M. Entre o individualismo e a solidariedade: dilemas da política e da cidadania no Rio de Janeiro. Revista Brasileira de Ciências Sociais, v. 15, n. 44, p. 73-90, 2000.

LEMGRUBER, J.; CANO, I.; MUSUMECI, L. Olho por olho? O que pensam os cariocas sobre "bandido bom é bandido morto". Rio de Janeiro: CESeC, 2017.

LIMA, R.; BUENO, S.; MINGARDI, G. Estado, polícias e segurança pública no Brasil. Revista Direito GV, v. 12, n. 1, p. 49-85, abr. 2016.

MARINS, V. Contratação de serviços de segurança privada pela administração pública: uma análise à luz da moderna privatização de poderes administrativos. Revista do Tribunal de Contas do Estado de Minas Gerais, v. 74, n. 1, p. 79- 102, jan.-mar. 2010.

McGREGOR, A. Politics, police accountability, and public health: civilian review in Newark, New Jersey. Journal of Urban Health, v. 93, n. 1, p. 141-153, apr. 2016. 
MOZZATO, A.; GRZYBOVSKI, D. Análise de conteúdo como técnica de análise de dados qualitativos no campo da administração: potencial e desafios. Revista de Administração Contemporânea, v. 15, n. 4, p. 731-747, jul.-ago. 2011.

OLIVEIRA, A. Empresas de vigilância no sistema de prestação de serviços de segurança patrimonial privada: uma avaliação da estrutura de governança. Tese de Doutorado apresentada à Escola Superior de Agricultura da

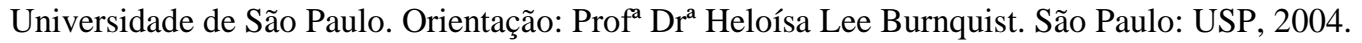

PAIXÃO, A. Segurança privada, direitos humanos e democracia: notas preliminares sobre novos dilemas políticos. Novos Estudos CEBRAP, n. 31, p.131-142, out. 1991.

PATTON, M. Qualitative evaluation and research methods. 2. ed. London: Sage, 1990.

PONCIONI, P. O modelo policial profissional e a formação profissional do futuro policial nas academias de polícia do estado do Rio de Janeiro. Sociedade e Estado, v. 20, n. 3, p. 585-610, set.-dez. 2005.

PROVENZA, M.; COSTA, J.; MIRANDA, I.; SILLI, M.; MARQUES, K. Homicídio doloso na cidade do Rio de Janeiro: Uma comparação entre as bases da segurança e da saúde. Revista Dilemas, v. 10, n.2, p. 297-321, mai.-ago. 2017.

RICARDO, C. Regulamentação, fiscalização e controle sobre a segurança privada no Brasil. Dissertação de Mestrado apresentada à Faculdade de Direito da Universidade de São Paulo. Orientação: Prof. Dr. José Eduardo Faria. São Paulo: USP, 2006.

SIAFAKA, M. Violência e delinquência como desafios da segurança pública: análise do fenômeno na cidade de São Paulo. Dissertação de Mestrado apresentada ao Departamento de Estudos Latino-americanos da Leiden University. Orientação: Prof Dr Pablo Isla Monsalve. Leiden: Leiden University, 2016.

SILVA, F; SILVA, K. O novo modelo de segurança pública no Rio de Janeiro: violação ou garantia de direitos humanos nas favelas cariocas? Revista Brasiliense de Pós-Graduação em Ciências Sociais, v. 1. p. 39-62, 2012.

SILVA, L. "Violência urbana", segurança pública e favelas - o caso do Rio de Janeiro atual. Cadernos CRH, v. 23 , n. 59, p. 283-300, mai.-ago. 2010.

SOARES, L. Novas políticas de segurança pública. Estudos Avançados, v. 17, n. 47, p.75-96, jan.-abr. 2003.

SOUZA, E.; MINAYO, M. Segurança pública num país violento. Cadernos de Saúde Pública, v. 33, n. 3, p. 1-4, 2017.

SOUTH, N. Privatizing policing in the European market: some issues for theory, policy, and research. European Sociological Review, v. 10, n. 3, p. 219-233, dez. 1994.

SPANIOL, M. Violência versus exercício da segurança pública em democracia no Brasil: um desafio a ser enfrentado. Revista de Graduação e Pós-Graduação em Ciências Sociais, v.3, n.2, p. 29-51, 2016

VERGARA, S. Métodos de coleta de dados no campo. 2. ed. São Paulo: Atlas, 2012.

ZALUAR, A. A cobra morde o próprio rabo. O Globo, 29 de janeiro de 2017. p. 11.

ZANETIC, A. A segurança privada no Brasil: alguns aspectos relativos às motivações, regulação e implicações sociais do setor. Revista Brasileira Adolescência e Conflitualidade, n. 3, p. 51-70, 2010. 